\title{
Parametric analysis of composite material in comparison with mild steel by experimental testing
}

\author{
C.M. Shetasandi* and B.B.Deshmukh
}

Department of Mechanical Engineering, Walchand Institute of Technology, Solapur-413004, India. Email: cshetasandi@gmail.com

The aim of this work is to perform parametric analysis of the composite material in comparison with mild steel by experimental testing. These analyses are useful for studying the behavior of composite material in comparison with mild steel. We have studied different combination of composite materials theoretically. Theoretical results show that the polymer matrix composite can give better results when comparing with mild steel. For making composite specimen E-glass fibre with polyester resin has used. The specimen has made by hand layup method. Following tests such as tensile, compression and hardness tests were conducted on both mild steel and composite specimen. The tensile strength of composite has found $258 \mathrm{MPa}$ but it fails under compressive load. The Rockwell hardness of composite as found $56 \mathrm{~kg}$. The failure of specimen under tension and compression has analyzed by scanning electron microscope (SEM). Tensile strength and Rockwell hardness of mild steel are $250 \mathrm{MPa}$, and 71 respectively.

Figure 1 shows the stress strain curve of composite material and mild steel in which tensile strength of composite specimen is slightly greater than mild steel. While the
Figure 2 and Figure 3 show that the failure is due to improper bonding of mixture, random fibre orientation and porosity.

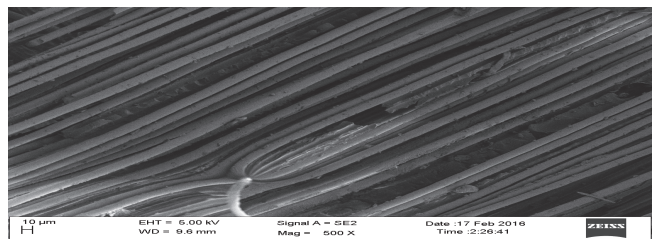

Figure 2: SEM image of tensile test specimen

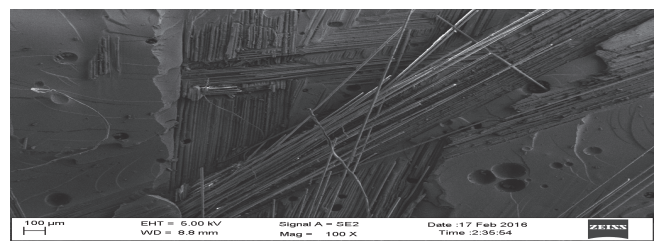

Figure 3: SEM image compression test specimen

\section{References}

1. C. Shetasandi, B. Deshmukh 'Parametric analysis by analystical method', (2015)

2. Penga $X$. etal Composites Science and Technology, (2004)

3. Weizhi Wang etal, European Polymer Journal $39(2003)$

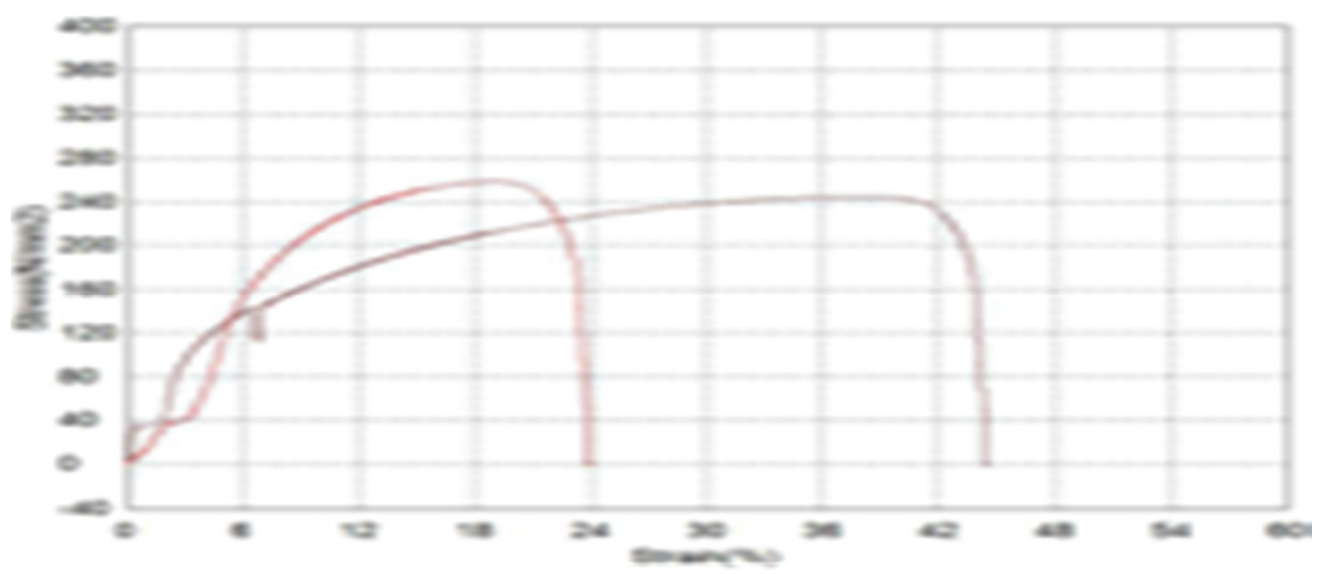

Figure 1: Stress-strain curve between mild steel and composite material 